\title{
Quantifying the global carbon cycle response to volcanic stratospheric aerosol radiative forcing using Earth System Models
}

\author{
A. M. Foley,,$^{1,2}$ M. Willeit, ${ }^{3}$ V. Brovkin, ${ }^{3,4}$ G. Feulner, ${ }^{3}$ and A. D. Friend ${ }^{1}$ \\ Received 27 February 2013; revised 10 November 2013; accepted 8 December 2013; published 15 January 2014.
}

[1] Large volcanic eruptions can have a significant cooling effect on climate, which is evident in both modern and palaeo data. However, due to the difficulty of disentangling volcanic and other influences in the modern atmospheric $\mathrm{CO}_{2}$ record, and uncertainties associated with palaeo reconstructions of atmospheric $\mathrm{CO}_{2}$, the magnitude of the carbon cycle response to volcanically induced climatic changes is difficult to quantify. In this study, three Earth System Models (SIMEARTH, CLIMBER-2, and CLIMBER LPJ) are used to simulate the effects of different magnitudes of volcanic eruption, from relatively small (e.g., Mount Pelée, 1902) to very large (e.g., the 1258 ice core event), on the coupled global climate-carbon cycle system. These models each use different, but justifiable, parameterizations to simulate the global carbon cycle and climate. Key differences include how soil respiration and net primary productivity respond to temperature and atmospheric $\mathrm{CO}_{2}$. All models simulate global surface cooling in response to volcanic events. In response to a Mount Pinatubo-equivalent eruption, the modelled temperature decrease is $0.3^{\circ} \mathrm{C}$ to $0.4^{\circ} \mathrm{C}$ and atmospheric $\mathrm{CO}_{2}$ decreases by $1.1 \mathrm{ppm}$ to $3.4 \mathrm{ppm}$. The initial response time of climate to volcanic forcing and subsequent recovery time vary little with changes in the size of the forcing. Response times for vegetation and soil carbon are relatively consistent across forcings for each model. However, results indicate that there is significant uncertainty concerning the response of the carbon cycle to volcanic eruptions. Suggestions for future research directed at reducing this uncertainty are given.

Citation: Foley, A. M., M. Willeit, V. Brovkin, G. Feulner, and A. D. Friend (2014), Quantifying the global carbon cycle response to volcanic stratospheric aerosol radiative forcing using Earth System Models, J. Geophys. Res. Atmos., 119, 101-111, doi:10.1002/2013JD019724.

\section{Introduction}

[2] The impact of volcanism on climate has been studied extensively [e.g., Schönwiese, 1988; Rampino and Self, 1993; Robock, 2000; Zielinski, 2000; Buggisch et al., 2010; Cole-Dai, 2010; Timmreck, 2012]. Through both the production of ash clouds and the emission of $\mathrm{SO}_{2}$, volcanic eruptions can lead to cooling. Ash clouds, by blocking sunlight, lead to cooling, however this effect is temporally limited as ash quickly settles due to gravity. $\mathrm{SO}_{2}$ is converted to sulphate aerosols in the troposphere and stratosphere, which also have a net cooling effect.

[3] Volcanic eruptions which only extend to the troposphere tend to have only a regional effect on climate, while

\footnotetext{
${ }^{1}$ Department of Geography, University of Cambridge, Cambridge, UK.

${ }^{2}$ Now at Cambridge Centre for Climate Change Mitigation Research (4CMR), Department of Land Economy, University of Cambridge, Cambridge, UK.

${ }^{3}$ Potsdam Institute for Climate Impact Research, Potsdam, Germany.

${ }^{4}$ Max Planck Institute for Meteorology, Hamburg, Germany.

Corresponding author: A. M. Foley, Cambridge Centre for Climate Change Mitigation Research (4CMR), Department of Land Economy, University of Cambridge, Cambridge CB3 9EP, UK. (amf62@cam.ac.uk)

(C)2013. American Geophysical Union. All Rights Reserved. 2169-897X/14/10.1002/2013JD019724
}

those that reach the stratosphere can have a global impact, as stratospheric winds distribute volcanic ash and aerosols over a greater area and residence time for stratospheric particles is significantly larger than for tropospheric particles [Parfitt and Wilson, 2008]. Furthermore, there is increasing evidence that clusters of volcanic eruptions can trigger long-lasting cooling [e.g., Miller et al., 2012; Schleussner and Feulner, 2013] and are thus a potentially important driver of climate variations, from short term to century scale, during the last millennium [Robock, 1979; Crowley, 2000; Feulner, 2011].

[4] Direct emissions of $\mathrm{CO}_{2}$ by recent volcanic eruptions are negligible [Frölicher et al., 2013]. The current estimate for the long-term annual average of volcanic carbon emissions is $0.26 \mathrm{GtCO}_{2}(0.07 \mathrm{GtC})$, though infrequent, large eruptions may cause deviations from that estimate [Gerlach, 2011]; individually, the Mount Pinatubo eruption of 1991 emitted approximately $0.05 \mathrm{GtCO}_{2}$ or $0.014 \mathrm{GtC}$, while anthropogenic $\mathrm{CO}_{2}$ emissions are on the order of $35 \mathrm{GtCO}_{2}$ per year [Gerlach, 2011].

[5] However, the abrupt perturbation to climate instigated by a volcanic eruption also impacts the carbon cycle. The cooling following eruptions has impacts on the dynamics of vegetation, soil, and marine carbon pools, which are less well characterized than the climatic impact. As volcanic eruptions are often considered a natural analogue to stratospheric aerosol injections as a 
geoengineering technique, it is important to study the response of the carbon cycle to such perturbations. Furthermore, the response of the carbon cycle to volcanism may be used to better understand the carbon cycle response to climate generally, which is quite uncertain [e.g., Arora et al., 2013].

[6] By studying volcanic forcings, we can avail of observation-based data to assess model-based outcomes against, although these data sources are not without limitations. Instrumental measurements of greenhouse gases and key climate variables only cover the recent past, during which the 1991 eruption of Mount Pinatubo was the only large (Volcanic Explosivity Index (VEI) 6 or higher) volcanic eruption to have occurred. Furthermore, the carbon cycle signal associated with smaller eruptions may be difficult to distinguish from natural variability.

[7] Reconstructions of past temperatures based on natural proxies such as tree rings are a rich data source for investigating fluctuations in past climate. However, the uncertainties associated with these reconstructions make it difficult to isolate the response of the climate system to the short-term forcing fluctuations associated with volcanism. A key source of uncertainty in these proxies is their climatic sensitivity and whether this sensitivity remains constant or not. In more recent periods, a discrepancy has been observed between instrumental measurements of temperature and reconstructions based on tree rings, a phenomenon known as the "divergence problem" [D'Arrigo et al., 2008], which suggests a reduction in the temperature sensitivity of tree growth, the causes of which are not well understood. Mann et al. [2012] demonstrated that trees close to the tree line have a reduced sensitivity to cooling, perhaps accounting for the underestimation of volcanic cooling in past centuries in temperature reconstructions based on tree rings.

[8] Other data sources which can be used to reconstruct temperature include speleothems, corals, ocean and lake sediments, and ice cores, amongst others [for an overview, see Jones et al., 2009]. No proxy is fully accurate; for example, sensitivity of speleothems depends on their rate of deposition; therefore, significant temperature changes occurring on a short timescale may not be detected in slowly deposited speleothems [McDermott, 2004]. Due to the differences in sensitivity of various proxies, as well as their geographic locations, data from multiple proxies are often combined to produce a temperature reconstruction [Mann, 2002].

[9] The subsequent effect of global cooling due to volcanism on the carbon cycle is even less certain. Earlier Earth System Model (ESM) studies of the effects of volcanic eruptions on $\mathrm{CO}_{2}$ [e.g., Cox and Jones, 2008 - Pinatubo; Brovkin et al., 2010 - 1258 eruption; Segschneider et al., 2013 - Yellowstone] reveal a small drop in atmospheric $\mathrm{CO}_{2}$ after an eruption, although the signal is masked by significant interannual variability in $\mathrm{CO}_{2}$ (e.g., due to ENSO).

[10] A key uncertainty is the vegetation response, which is influenced not only by temperature and precipitation fluctuations but also potentially by the increase in diffuse radiation following an eruption.

[11] It has been proposed that following the 1991 Mount Pinatubo eruption, there was an enhancement of the terrestrial carbon sink [Roderick et al., 2001; Ciais et al., 1995]. Lucht et al. [2002] attribute the enhanced carbon uptake to the boreal zone, while others attribute it to the tropical zone [Cox and Jones, 2008; Baker et al., 2006; Brovkin et al., 2010]. In a study of Harvard Forest, Gu et al. [2003] attributed the effect to an increase in photosynthesis caused by enhanced diffuse radiation, yet Barford et al. [2001] suggest that net primary productivity (NPP) in Harvard Forest during 1992 was minimal rather than maximal for the period 1992-2000. Using the JULES model, Mercado et al. [2009] conclude that diffuse radiation is a major contributor to the modelled land sink anomaly in 1992, though by the following year, this effect has diminished. Angert et al. [2004] found that global NPP could not have increased following the eruption, while Krakauer and Randerson [2003] find evidence in midlatitude and high-latitude northern tree rings to suggest that any enhancement of NPP due to an increase in diffuse light following a volcanic event is offset by the detrimental effect of volcanic cooling.

[12] Compared to the modern observational record, reconstructions of past atmospheric $\mathrm{CO}_{2}$ concentrations cover more volcanic eruptions, but are affected by uncertainties and limitations which make it difficult to identify signals of past volcanism in the data. Unlike temperature reconstructions from ice cores, which are based on oxygen isotope measurements from the ice itself, $\mathrm{CO}_{2}$ reconstructions use measurements of $\mathrm{CO}_{2}$ concentration in air bubbles within the ice. As such, an important issue relating to the use of ice cores to reconstruct past atmospheric conditions is the age difference between the air in ice bubbles and the surrounding ice. The air in ice bubbles is always younger than the surrounding ice and hence reflective of atmospheric conditions at a later point in time than the time of snow deposition, because the air between snow crystals remains exposed to the atmosphere during the slow transformation from snow to firn and then ice. Additionally, this lag time, known as "pore close off" [Bradley, 1999], varies depending on accumulation rates. Furthermore, since bubbles in the same stratum may have been sealed at different times, a single ice sample may represent atmospheric conditions across several decades to centuries. This consideration has important implications when attempting to identify signals of past perturbations due to volcanic activity, as these events have a much shorter timescale. Therefore, due to the short timescales on which such perturbations occur, the effects of past volcanic activity on atmospheric $\mathrm{CO}_{2}$ concentration may not be apparent in ice core records, although ice cores provide an important long-term perspective on atmospheric concentrations of $\mathrm{CO}_{2}$ [e.g., Fischer et al., 1999; Indermühle et al., 1999; Lüthi et al., 2008]. Model validation is further complicated by the fact that a specific volcanic eruption may be recorded in the sulphate record but not in the $\mathrm{CO}_{2}$ or temperature proxy data, as is the case for the 1258 eruption [Mann et al., 2008; Ahn et al., 2012], even when the natural smoothing of the ice core $\mathrm{CO}_{2}$ record is accounted for.

[13] Given the uncertainties associated with relevant data sources, model simulations of the impacts of past volcanism on the climate-carbon cycle cannot be robustly evaluated through direct model-data comparison. Yet, evaluating how models simulate this effect is not only a useful test of ESMs, but also of critical relevance given current debates relating to geoengineering of climate using stratospheric sulphate aerosols [Wigley, 2006; Rasch et al., 2008]. Therefore, this research investigates the simulated response of the global carbon cycle to this type of perturbation in a hierarchy of ESMs by characterizing the response using key quantities that have been used to summarize ESM responses in previous projects, and which are relevant to the response of a model to 
volcanically induced radiative forcing perturbations, such as carbon cycle sensitivity to climate $(\gamma)$ [Frank et al., 2010] and the land carbon sensitivity to $\mathrm{CO}_{2}\left(\beta_{\mathrm{L}}\right)$ [Friedlingstein et al., 2006]. While these other studies are not of volcanic effects, and although values of $\gamma$ and $\beta_{\mathrm{L}}$ vary depending on experimental setup [e.g., Plattner et al., 2008; Gregory et al., 2009; Zickfeld et al., 2011], they can be useful in interpreting model outcomes when observational data are insufficient to traditionally validate the models. The models are also compared with observational estimates of the cooling associated with the Mount Pinatubo eruption. The response and recovery times of the climate and carbon pools to the volcanic perturbation are also quantified to characterize the model response.

\section{Methods}

\subsection{Models}

[14] As the literature demonstrates, the response of the carbon cycle to large climate perturbations is highly uncertain, with a notable lack of agreement on what processes contributed to the enhanced carbon sink post-Pinatubo. As such, it is unclear what level of process understanding a model needs to have in order to skilfully model these climate-carbon feedbacks.

[15] Here we consider how simpler classes of model (e.g., SIMEARTH) perform relative to more complex Earth System Models of Intermediate Complexity (EMICs), to investigate the impact of model complexity on simulated climate-carbon cycle interactions. The models chosen capture first-order effects and use different suites of processes. Atmosphere-ocean General Circulation Models (AOGCMs) are not included in this study, although it is worth noting that certain processes that may be included in such models, but not in the simpler models selected here, may be relevant in the response of the carbon cycle to volcanic forcing. Eruptions of increasing magnitude are modelled to assess if key model sensitivities are constant, or if nonlinearities in the climate system are to be expected.

[16] SIMEARTH, a zero-dimensional simple ESM, is a tool with which to integrate, as parsimoniously as possible, coupled biogeochemistry-climate processes. SIMEARTH simulates the surface temperature response to radiative forcing using three thermal components, which react on fast, medium and slow timescales, and are fitted to the NASA GISS modelE GCM response to doubled $\mathrm{CO}_{2}$ using a coupled dynamical ocean [Friend, 2011; Hansen et al., 2005]. First-order parameterizations for air-sea and air-land $\mathrm{CO}_{2}$ fluxes enable the representation of carbon cycle processes and feedbacks in the Earth System. The $\mathrm{pCO}_{2}$ difference $\left(\Delta \mathrm{pCO}_{2}\right)$ between the overlying air and the sea surface governs the direction and rate of the net transfer of $\mathrm{CO}_{2}$ [Takahashi et al., 2002]. Gross primary production (GPP) on land is modelled as a logarithmic function of $\mathrm{CO}_{2}$ [Koch and Mooney, 1996]. Autotrophic respiration $\left(\mathrm{R}_{\mathrm{A}}\right)$ and heterotrophic respiration $\left(\mathrm{R}_{\mathrm{H}}\right)$ on land are assumed to be temperature dependent using a $\mathrm{Q}_{10}$ approach, with $\mathrm{R}_{\mathrm{A}}$ linearly proportional to the mass of carbon in the vegetation pool, and $\mathrm{R}_{\mathrm{H}}$ linearly proportional to the total soil carbon. Carbon pool dynamics are represented according to Foley and Ramankutty [2004]. Importantly, hydrology is not represented in the model.

[17] The simpler modelling approach of SIMEARTH is compared with the more complex approaches of CLIMBER-2 and CLIMBER LPJ. CLIMBER-2 [Petoukhov et al., 2000] is an EMIC. It comprises a 2.5-dimensional dynamical-statistical atmosphere with a spatial resolution of $10^{\circ}$ in latitude and $51^{\circ}$ in longitude, a three-basin zonally averaged ocean, and a sea-ice model with $2.5^{\circ}$ latitudinal resolution. It also includes a terrestrial vegetation model and a module for ocean biogeochemistry [Brovkin et al., 2002]. CLIMBER-2 was validated against present-day climate and compares favourably with more comprehensive climate models [Ganopolski et al., 2001]. It has been used extensively in paleoclimatic studies [Claussen et al., 1999], such as simulations of the transient response of the climate system to the forcings of the last millennium [Bauer et al., 2003; Eby et al., 2013]. In its standard version, referred to in this paper as CLIMBER-2, the terrestrial vegetation model is VECODE [Brovkin et al., 1997].

[18] VECODE is a dynamic global vegetation model [Brovkin et al., 1997; Brovkin et al., 2002]. It distinguishes two plant functional types (PFTs): forest and grass. Vegetation carbon is aggregated into a "fast" pool of green biomass (leaves) and a "slow" pool of structural biomass (stems, roots). Dead organic matter is described by two pools: a "fast" compartment (woody residues) and a "slow" compartment (humus). Annual carbon pool dynamics are simulated separately for trees and grass. In this study, we use a new parameterization for NPP that differs from the standard version of VECODE described in Brovkin et al. [2002]. This new parameterization is based on a simple daily light use efficiency model following Potter et al. [1993] and Horn and Schulz [2011]. NPP is the product of the photosynthetically active radiation absorbed by the vegetation and a light utilization efficiency that is modified by temperature and evaporative fraction [Horn and Schulz, 2011]. $\mathrm{CO}_{2}$ fertilization is included in the model. The allocation of carbon to the biomass pools is controlled by NPP with increasing allocation to structural biomass as NPP increases. The turnover times of the biomass pools are assumed to be functions of NPP. We also introduced a new parameterization for the turnover time of soil carbon which depends on the mean annual temperature following a $\mathrm{Q}_{10}$ approach with a value $\mathrm{Q}_{10}=2$. The reference turnover time at $5^{\circ} \mathrm{C}$ is from Schimel et al. [1994]. Vegetation areal cover reacts to any climate change with a relaxation toward a new equilibrium with a timescale determined by the turnover time of the structural biomass.

[19] A second version, referred to here as CLIMBER LPJ, is also used in which the vegetation model is the LPJ dynamic global vegetation model [Sitch et al., 2003]. LPJ simulates the seasonal- to century-scale dynamics of land biogeochemistry and vegetation dynamics. It incorporates a coupled photosynthesis-water balance scheme, plant resource competition, population dynamics, fire disturbance, and soil biogeochemistry. Compared with VECODE, LPJ includes more plant and ecosystem mechanisms, distinguishes a larger set of 10 PFTs, is applied at a higher spatial resolution of $0.5^{\circ}$, and can simulate seasonal land carbon and water dynamics. In CLIMBER LPJ, soil respiration depends on both temperature and soil moisture, with temperature dependence following a modified Arrhenius equation.

[20] In the CLIMBER LPJ setup, LPJ is driven by monthly CLIMBER-2 near surface air temperature, precipitation, and cloudiness using an anomaly approach. Thirty years of data from the CRU observational climatology is used as a baseline. Global annual changes in the vegetation, litter, and soil 


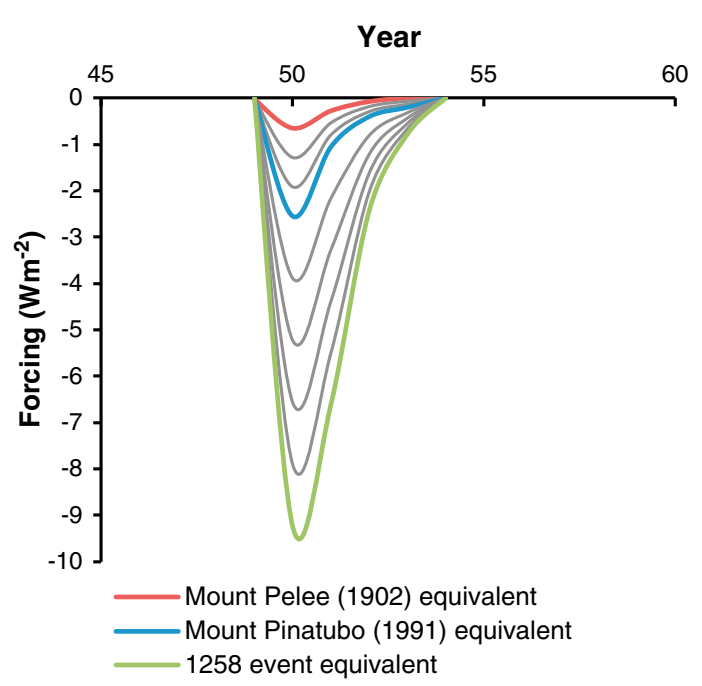

Figure 1. Idealized volcanic radiative forcings.

carbon pools computed by LPJ are then used at the end of each year to update the atmospheric $\mathrm{CO}_{2}$ concentration used in CLIMBER-2 for simulating the climate of the following year. LPJ is used to simulate the biogeochemical processes on land and interacts with atmospheric $\mathrm{CO}_{2}$, while changes in albedo, evapotranspiration, and roughness are simulated by the land surface module of CLIMBER-2. A more detailed description of how the two models are coupled can be found in Sitch et al. [2005].

\subsection{Volcanic Forcing}

[21] All models are used to run "pulse" experiments for volcanic events of varying magnitude, to simulate the climate-carbon cycle response to volcanism and the subsequent longer-term recovery. Using the radiative forcings of Hegerl et al. [2006], which are derived from sulphate measurements in nine ice cores, the magnitude and shape of the signals of three volcanic events are extracted: the Mount Pelée eruption of 1902 (VEI 4), the Pinatubo eruption of 1991 (VEI 6), and the 1258 ice core event (VEI 7), the largest event in the last 1000 years of ice core sulphate data sets. Interpolation between these three events yields a set of scaled annual global radiative forcings for intermediate-sized events, centred at year 50 of the simulations (Figure 1). Volcanic forcing is then implemented in the models as a prescribed change in radiative forcing, applied at the top of the atmosphere.

\subsection{Calculation of Climate-Carbon Cycle Response Characteristics}

[22] The global temperature response to volcanic radiative forcing, or "volcanic climate sensitivity" $\left({ }^{\circ} \mathrm{C} / \mathrm{Wm}^{-2}\right)$, for each volcanic event, is computed as the ratio between the integrated global mean temperature anomaly and the integrated radiative forcing associated with that event, both calculated over 50 years from the commencement of each eruption. The carbon cycle sensitivity to climate is quantified by $\gamma\left(\mathrm{ppm} /{ }^{\circ} \mathrm{C}\right)$, here calculated as the ratio of the maximum change in atmospheric $\mathrm{CO}_{2}$ to the maximum decrease in temperature following a volcanic eruption. As these are idealized experiments in which the only perturbation is the prescribed volcanic forcing, it can be assumed that the initial drop in $\mathrm{CO}_{2}$ is mainly in response to the climatic perturbation. This approach varies from that of
Friedlingstein et al. [2006], in which the differences in atmospheric $\mathrm{CO}_{2}$ due to climate changes (induced by $\mathrm{CO}_{2}$ forcing) were calculated as a difference between simulations with interactive $\mathrm{CO}_{2}$ and climate (coupled) and interactive $\mathrm{CO}_{2}$ (uncoupled), therefore considering together the effect of climate change and $\mathrm{CO}_{2}$ on the carbon cycle. Also, in the present study, $\gamma$ is calculated as the ratio between peak $\mathrm{CO}_{2}$ and temperature response, while Friedlingstein et al. [2006] calculated $\gamma$ as this ratio from simultaneous changes in these variables. Our approach also differs to that of Arora et al. [2013], who computed $\gamma$ from radiatively coupled simulations only (i.e., without a concomitant atmospheric $\mathrm{CO}_{2}$ increase). Our methodology is more similar to the approach of Frank et al. [2010], who also considered $\gamma$ as the change in atmospheric $\mathrm{CO}_{2}$ concentrations given a change in temperature. However, it must be recognized that values of $\gamma$ calculated under different experimental setups, including different forcing conditions and timescales, are not directly comparable.

[23] To isolate the land carbon sensitivity to $\mathrm{CO}_{2}, \beta_{\mathrm{L}}$ $(\mathrm{GtC} / \mathrm{ppm})$, a second set of simulations is run, in which temperature is kept constant and atmospheric $\mathrm{CO}_{2}$ is prescribed as the simulated $\mathrm{CO}_{2}$ from the coupled simulations. This is similar to the approach of Plattner et al. [2008], Gregory et al. [2009], and Zickfeld et al. [2011], in which the land carbon sensitivity is quantified using simulations in which $\mathrm{CO}_{2}$ is prescribed but does not affect climate. In this study, $\beta_{\mathrm{L}}$ is calculated as the ratio of the maximum change in total land carbon to the maximum change in atmospheric $\mathrm{CO}_{2}$. This approach to the calculation of $\beta_{\mathrm{L}}$ also differs from that of other studies [e.g., Friedlingstein et al., 2006; Arora et al., 2013] as it uses peak values in land carbon uptake and atmospheric $\mathrm{CO}_{2}$. It must be noted that values of $\beta_{\mathrm{L}}$ calculated under different experimental setups are not directly comparable.

[24] Vegetation and soil carbon sensitivities to climate $\left(\mathrm{GtC} /{ }^{\circ} \mathrm{C}\right)$ are also computed and are quantified as the ratio of the initial peak changes in carbon content of the respective pools to the maximum change in temperature.

[25] To quantify the temporal dynamics of mean global annual temperature, $\mathrm{CO}_{2}$, and the vegetation and soil carbon pools, response and recovery times are also calculated. Response times are calculated as the time lag between eruption and the first peaks in the time series. The recovery time represents the characteristic time it takes the system components to relax toward the pre-eruption values. We take the time between peak response and recovery to one third of the peak response anomaly. For $\mathrm{CO}_{2}$, the time to recover from the positive anomaly peak to one third of the peak is used.

[26] As CLIMBER-LPJ includes a representation of natural climate variability, only simulations in which the signal of the volcanic eruption is distinguishable from this natural variability are used to calculate sensitivities, response, and recovery times. The volcanic signal was considered distinguishable if it was at least three times larger than the standard deviation of the pre-eruption time series.

\section{Results}

\subsection{Model Responses to Volcanic Forcings}

[27] Figure 2 illustrates the modelled climate-carbon cycle response of the ESMs to volcanic forcings of different magnitudes spanning the radiative forcing range of three real volcanic eruptions. 
FOLEY ET AL.: ESM CARBON CYCLE RESPONSE TO VOLCANISM

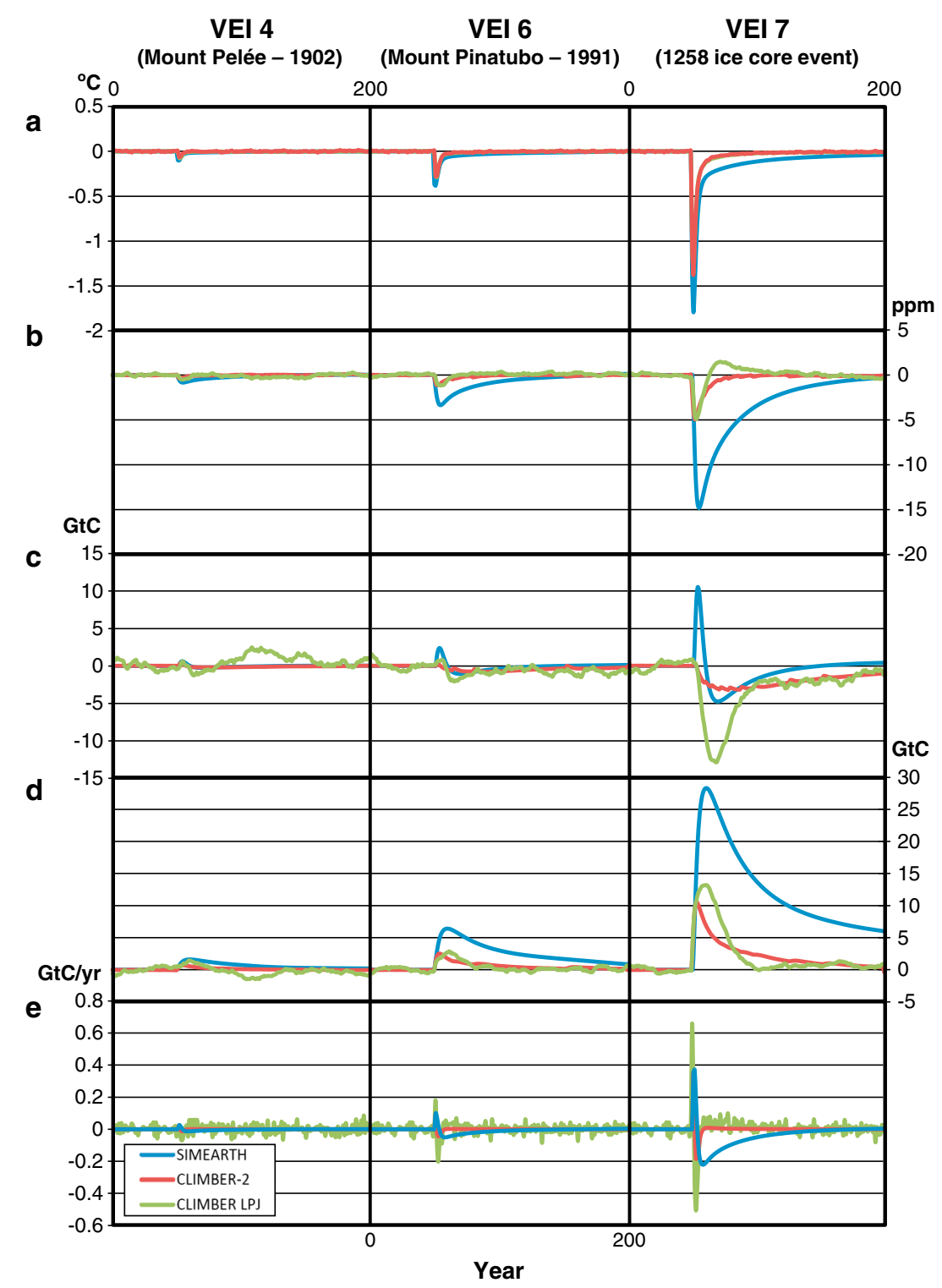

Figure 2. Responses of SIMEARTH (blue), CLIMBER-2 (red), and CLIMBER LPJ (green) models to volcanic forcings: (a) temperature anomalies, (b) atmospheric $\mathrm{CO}_{2}$ anomalies, (c) vegetation carbon anomalies, (d) soil carbon anomalies, and (e) ocean-atmosphere $\mathrm{CO}_{2}$ exchange. Anomalies are calculated with respect to pre-eruption mean values.

[28] All models simulate a decrease in global annual mean surface air temperature in response to volcanic forcing (Figure 2a). For the largest forcing, equivalent to the 1258 ice core event, this drop in temperature ranges from $-1.35^{\circ} \mathrm{C}$ in CLIMBER-2 to $-1.79^{\circ} \mathrm{C}$ in SIMEARTH. After a short period of strong cooling, temperature begins to recover toward pre-eruption levels.

[29] The annual mean temperature decrease associated with a Pinatubo-sized event ranges from $0.3^{\circ} \mathrm{C}$ (CLIMBER-2) to $0.4^{\circ} \mathrm{C}$ (SIMEARTH). Observational estimates for the Pinatubo eruption, with the confounding effect of the ENSO signal removed, suggest that peak values between -0.3 and $-0.5^{\circ} \mathrm{C}$ in monthly surface air temperature data are plausible [Wigley, 2000; Santer et al., 2001; Yang and Schlesinger, 2001]; more recent studies considering the effects of both ENSO and solar irradiance variations on global mean temperature find monthly peak values in the range -0.3 to $-0.4^{\circ} \mathrm{C}$
[Lean and Rind, 2008; Foster and Rahmstorf, 2011], in good agreement with the simulated values.

[30] Carbon cycle responses are more variable between the ESMs (Figure 2b). Atmospheric $\mathrm{CO}_{2}$ decreases by $15 \mathrm{ppm}$ in the SIMEARTH simulation of the 1258 ice core event, compared with decreases of $5 \mathrm{ppm}$ in the CLIMBER LPJ and CLIMBER-2 simulations.

[31] Figure 3 illustrates the timescales on which temperature and the various carbon pools respond across the different models, taking the 1258-equivalent forcing as an example, and illustrates that in CLIMBER LPJ, after a smaller initial decrease due to reduced heterotrophic respiration at lower temperatures, atmospheric $\mathrm{CO}_{2}$ increases compared with pre-eruption levels due to a decrease and subsequent slow recovery of vegetation carbon.

[32] The models diverge considerably in their representations of the vegetation carbon response (Figure 2c). In SIMEARTH, 
FOLEY ET AL.: ESM CARBON CYCLE RESPONSE TO VOLCANISM
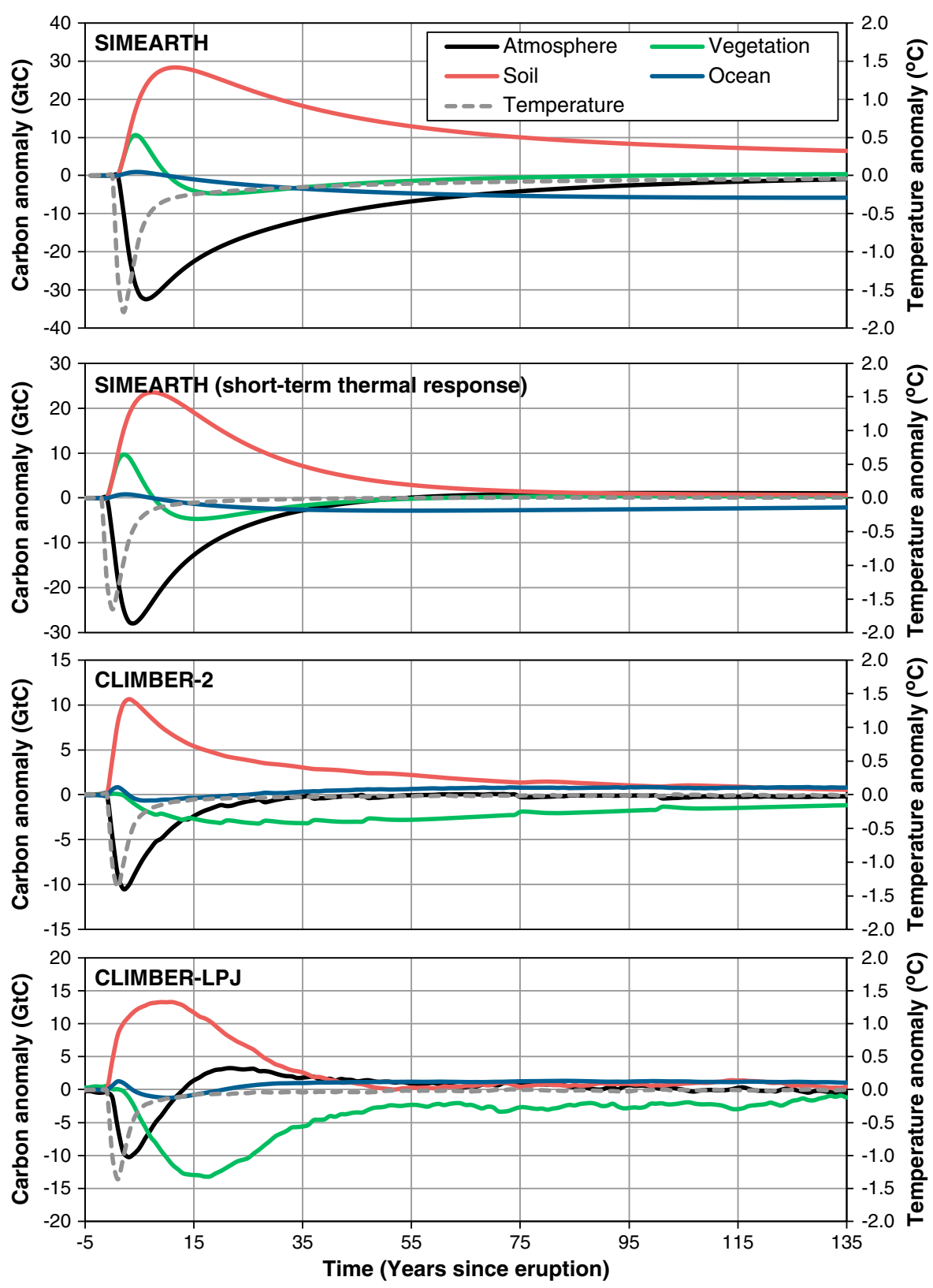

Figure 3. Responses of (a) SIMEARTH, (b) CLIMBER-2, and (c) CLIMBER LPJ models to 1258-ice core event equivalent radiative forcing, for temperature anomalies (grey dashed), atmospheric carbon anomalies (black), vegetation carbon anomalies (green), soil carbon anomalies (red), and ocean carbon anomalies (blue).

vegetation carbon is initially higher after eruptions, as cooling leads to a reduction in autotrophic respiration. After this initial response to temperature change, vegetation carbon falls to less than pre-eruption values in response to the decrease in atmospheric $\mathrm{CO}_{2}$. NPP in this model is parameterized as a function of atmospheric $\mathrm{CO}_{2}$ and not temperature; therefore, as atmospheric $\mathrm{CO}_{2}$ decreases, so does NPP and correspondingly vegetation carbon. Conversely, in both CLIMBER-2 and CLIMBER LPJ, there is a decrease in vegetation carbon storage after eruptions, as in addition to the $\mathrm{CO}_{2}$ dependence, NPP is parameterized also as a function of climate variables including temperature and precipitation.
[33] For the 1258 event equivalent simulation, soil carbon increases by $10.6 \mathrm{GtC}$ in CLIMBER-2, $13.8 \mathrm{GtC}$ in CLIMBER LPJ, and $28.3 \mathrm{GtC}$ in SIMEARTH, before decaying to pre-eruption levels (Figure 2d). This intermodel variability can be explained by the use of difference parameterizations for the temperature dependency of soil respiration. Further analysis, in which the longer-term (medium and slow) thermal response components in SIMEARTH were uncoupled (Figure 3), indicates that in SIMEARTH, the long overall thermal response of the EBM is responsible for the slow recovery of soil carbon. This long response is likely exaggerated as the full EBM does not distinguish land and ocean temperatures, the former of which are likely to decay 

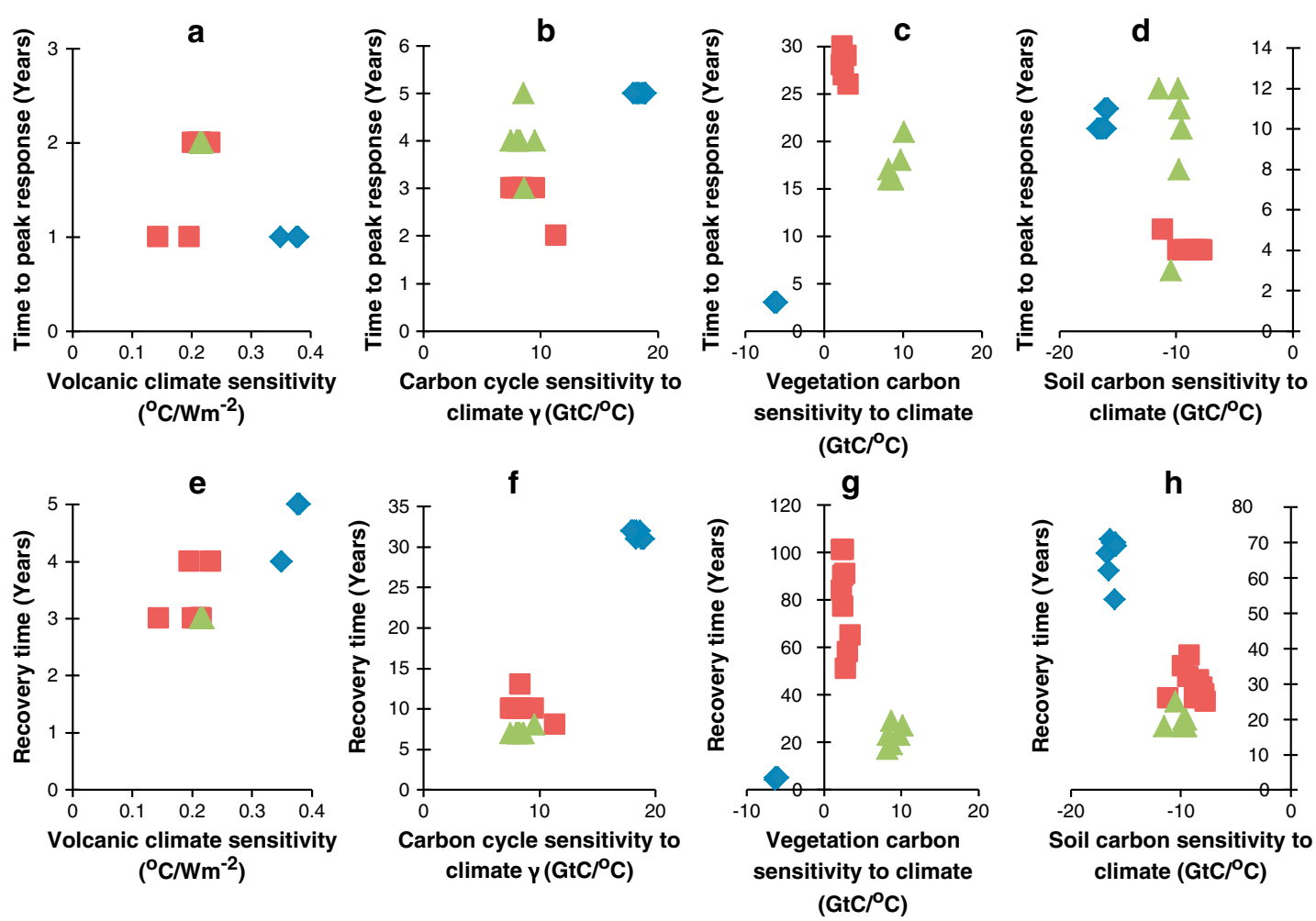

SIMEARTH

CLIMBER-2

$\triangle$ CLIMBER LPJ

Figure 4. Magnitude of response versus (top) response time and (bottom) recovery time for (left to right) climate response to radiative forcing, i.e., "volcanic climate sensitivity" $\left({ }^{\circ} \mathrm{C} / \mathrm{Wm}^{-2}\right)$, atmospheric $\mathrm{CO}_{2}$ response to temperature change, i.e., $\gamma\left(\mathrm{GtC} /{ }^{\circ} \mathrm{C}\right)$, vegetation carbon response to temperature change $\left(\mathrm{GtC} /{ }^{\circ} \mathrm{C}\right)$ and soil carbon response to temperature change $\left(\mathrm{GtC} /{ }^{\circ} \mathrm{C}\right)$.

back to their previous equilibrium values significantly faster than ocean surface temperatures.

[34] In all models, after an initial response of carbon uptake, the marine surface flux declines to a value lower than its pre-eruption levels before recovering (Figure 2e). Initially, the cooling effect of the eruption on surface ocean water leads to an increase in $\mathrm{CO}_{2}$ solubility in surface waters, and a higher degree of $\mathrm{CO}_{2}$ uptake by the ocean, which is captured by all three models. Then, $\mathrm{CO}_{2}$ in the atmosphere becomes important. Significant land uptake in CLIMBER LPJ causes a drop in atmospheric $\mathrm{CO}_{2}$ and the ocean reacts by outgassing carbon. CLIMBER LPJ's ocean flux increases again, in response to the recovery of vegetation carbon and atmospheric $\mathrm{CO}_{2}$, before stabilizing near pre-eruption levels (Figure 2). In SIMEARTH, ocean carbon appears less sensitive to atmospheric $\mathrm{CO}_{2}$ relative to the other models. Across the models, however, changes in marine flux posteruption are quite small; the ocean sink is weaker than the land on short time scales, but can become more important on longer time scales.

\subsection{Quantification of Model Responses and Sensitivities}

[35] Figure 4 describes relationships between key characteristics of the simulated climate-carbon cycle responses across the three models, the sensitivity of the response and the response time, calculated from the full suite of radiative forcings.

[36] It is evident from Figure 4 that volcanic climate sensitivity varies little with changes in the size of the forcing.
The response and recovery time of climate to volcanic forcing are largely consistent in all three models regardless of the size of the forcing (Figures $4 \mathrm{a}$ and $4 \mathrm{e}$ ). It is interesting to note the occurrence of larger carbon cycle recovery times in SIMEARTH, the model with the highest carbon cycle sensitivities to climate (Figures $4 \mathrm{~b}$ and $4 \mathrm{f}$ ), due to the slow recover of soil carbon, which corresponds to the long overall thermal response of the EBM.

[37] Response times for vegetation and soil carbon (Figures $4 \mathrm{c}$ and 4d) are relatively consistent across forcings for each model. Vegetation recovery time is more variable in CLIMBER-2 and CLIMBER LPJ than in SIMEARTH (Figure 4g). CLIMBER-2 experiments also exhibit much longer vegetation carbon recovery times than the other models, as this model simulates some vegetation die-off in response to volcanic cooling and the time scale for forest regrowth is of the order of 25-90 years [Brovkin et al., 2002]. Soil carbon sensitivities tend to remain relatively constant across the range of forcings.

[38] Generally, all computed sensitivities and response/ recovery times for CLIMBER LPJ show a larger spread between the different forcings. This is because CLIMBER LPJ includes natural variability arising from the 30 years CRU background climate used in the anomaly coupling approach. Particularly, when the response signal is small, as in the cases of small radiative forcing, the interannual variability introduces a random component in the computed values. 


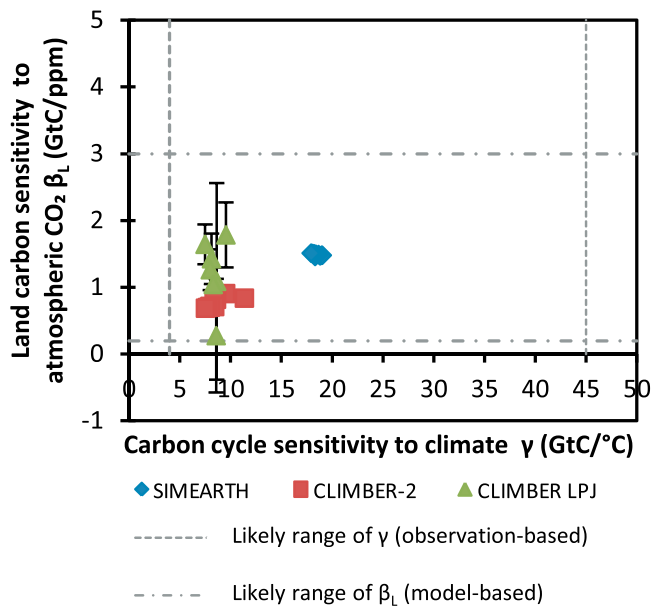

Figure 5. Atmospheric $\mathrm{CO}_{2}$ response to temperature change, $\gamma\left(\mathrm{GtC} /{ }^{\circ} \mathrm{C}\right)$, versus total land carbon response to $\mathrm{CO}_{2} \beta_{\mathrm{L}}(\mathrm{GtC} / \mathrm{ppm})$, with constraints.

\subsection{Comparison of Key Sensitivities With Published Estimates}

[39] Figure 5 compares two key sensitivities, the carbon cycle response to climate, $\gamma$, and the land carbon sensitivity to $\mathrm{CO}_{2}, \beta_{\mathrm{L}}$, with values provided by other studies, either based on observational or modelled data. The ocean response to $\mathrm{CO}_{2}$ is quite small on the timescales considered here; therefore, we do not present estimates of $\beta_{\mathrm{O}} \beta_{\mathrm{L}}$ values for CLIMBER LPJ are supplied with error bars, as the manner in which this model is forced (using observational climate data) leads to large uncertainties which are not present in the other models. $\gamma$ uncertainties are smaller than $\beta$ uncertainties because the signal is larger, as the land response to climate is larger than the response to $\mathrm{CO}_{2}$.

[40] In the published literature, some attention has been given to developing constraints on $\gamma$, which are converted here to units of $\mathrm{GtC} /{ }^{\circ} \mathrm{C}$. Frank et al. [2010] provided estimates with respect to atmospheric $\mathrm{CO}_{2}$ based on a sophisticated analysis of temperature and $\mathrm{CO}_{2}$ trends over the last 1000 years, with emphasis on multidecadal to centennial dynamics, placing $\gamma$ in a likely range of $3.6 \mathrm{GtC} /{ }^{\circ} \mathrm{C}$ to $44.9 \mathrm{GtC} /{ }^{\circ} \mathrm{C}$, with a median of $16.2 \mathrm{GtC} /{ }^{\circ} \mathrm{C}$.

[41] Estimates of $\gamma$ have also been derived in model-based studies. For example, Rafelski et al. [2009] obtained estimates for the land component of $\gamma$, from varying configurations of a simple land biosphere model. Arora et al. [2013] calculated a range of $21.4 \mathrm{GtC} /{ }^{\circ} \mathrm{C}$ to $100.7 \mathrm{GtC} /{ }^{\circ} \mathrm{C}$ from radiatively coupled ESMs for the atmospheric component of $\gamma$. Importantly, as the values of Arora et al. [2013] were calculated for a scenario where $\mathrm{CO}_{2}$ increases at a rate of $1 \% \mathrm{yr}^{-1}$, they are unlikely to be directly comparable to the effect of a volcanic perturbation due to differences in the temporal dynamics of the forcings.

[42] Observational constraints on global $\beta_{\mathrm{L}}$ are also quite uncertain, due to the relatively small change in $\mathrm{CO}_{2}$ over observational periods (including glacial-interglacial cycles), the impact of land use changes, and the difficulty of disentangling climate and $\mathrm{CO}_{2}$ effects on the carbon system in observations. As such, observation-based studies tend to consider the climate and $\mathrm{CO}_{2}$ effects together, rather than separately, so that constraints on $\beta_{\mathrm{L}}$ are very much dependent on the value of $\gamma$ [e.g., Cox and Jones, 2008]. However, there have been several attempts to quantify $\beta_{\mathrm{L}}$ using climate-carbon cycle models. Friedlingstein et al. [2006] calculated $\beta_{\mathrm{L}}$ using models only, simulating the response of the carbon cycle on centennial scales to Special Report on Emissions Scenarios (SRES) A2 emissions scenario and found that $\beta_{\mathrm{L}}$ ranged from 0.2 to $2.8 \mathrm{GtC} / \mathrm{ppm}$. Rafelski et al. [2009] state a similar range (0.27-2.91 GtC/ppm). Arora et al. [2013] report terrestrial $\beta_{\mathrm{L}}$ fvalues of $0.22-1.46 \mathrm{GtC} / \mathrm{ppm}$, based on simulations using the CMIP5 Earth system models. As such, while we do not have rigorous observation-based constraints on $\beta_{\mathrm{L}}$, other modelbased estimates suggest a likely range of $0.2-3 \mathrm{GtC} / \mathrm{ppm}$.

[43] Even for the same underlying system behaviour, values of $\gamma$ and $\beta_{\mathrm{L}}$ can vary depending on experimental setup, such as the type of forcing and initial state [e.g., Plattner et al., 2008; Gregory et al., 2009; Zickfeld et al., 2011]; therefore, values of $\gamma$ and $\beta_{\mathrm{L}}$ calculated under different forcings and experimental setups are not directly comparable. As such, we do not attempt any kind of formal comparison of previously published values with the modelled $\gamma$ and $\beta_{\mathrm{L}}$ values presented here. Nevertheless, in the absence of adequate observational data with which to validate the models, comparison with these studies is a useful means of evaluating the modelled $\gamma$ and $\beta_{\mathrm{L}}$ values. CLIMBER-LPJ was included in both the Frank et al. [2010] and Friedlingstein et al. [2006] studies; the value of $\gamma$ calculated here is similar to that in Frank et al. [2010] and the value of $\beta_{\mathrm{L}}$ is similar to that in Friedlingstein et al. [2006] SIMEARTH is clearly close to the median $\gamma$ of Frank et al. [2010], with a mean $\gamma$ of $18.5 \mathrm{GtC} /{ }^{\circ} \mathrm{C}$. While the literature suggests that $\gamma$ is controlled by NPP, soil respiration, and marine solubility and upwelling, SIMEARTH contains no marine circulation. In SIMEARTH, NPP and soil respiration are parameterized very simply, the former as a function of atmospheric $\mathrm{CO}_{2}$ and the later as a function of temperature using a $\mathrm{Q}_{10}$ approach.

[44] CLIMBER-2 and CLIMBER LPJ are also within the likely range of values of Frank et al. [2010]. Using CLIMBER-2, $\gamma$ values range from 7.5 to $11.4 \mathrm{GtC} /{ }^{\circ} \mathrm{C}$, with a mean value of $8.6 \mathrm{GtC} /{ }^{\circ} \mathrm{C}$. Simulations using CLIMBER LPJ yield $\gamma$ values ranging from 7.5 to $9.5 \mathrm{GtC} /{ }^{\circ} \mathrm{C}$, with a mean value of $8.4 \mathrm{GtC} /{ }^{\circ} \mathrm{C}$. The $\gamma$ values for CLIMBER-2 and CLIMBER-LPJ are very similar and are determined mainly by the soil carbon increase as a response to cooling. The impact of vegetation effect on the atmospheric $\mathrm{CO}_{2}$ response, and thus on $\gamma$, is small in both models, in CLIMBER-2 because the drop in vegetation carbon is small and in CLIMBER-LPJ because the response time of vegetation to the eruption is slower. Ocean carbon changes are small and give a negligible contribution to the changes in $\mathrm{CO}_{2}$.

[45] $\beta_{\mathrm{L}}$ fvalues between the models are reasonably similar, centred around $1.2 \mathrm{GtC} / \mathrm{ppm}$, although as previously discussed, there are large uncertainties associated with CLIMBER LPJ simulations due to the climatological forcings employed with this model.

\section{Discussion and Conclusions}

[46] In this study, three models were used to characterize the global temperature and carbon cycle responses to volcanic stratospheric aerosol radiative forcing. All the models 
contain defensible parameterizations and account for land cover types with varying levels of complexity, yet yield very different behaviours. Although there are some differences in carbon cycle responses due to differing parameterizations, all three models are consistent with current knowledge of the coupled climate-carbon cycle system. The models are also mostly consistent with the ranges of $\gamma$ and $\beta_{\mathrm{L}}$ derived in other studies, although observational constraints on both parameters are poor.

[47] In response to a Pinatubo-equivalent anomaly in radiative forcing, in SIMEARTH, CLIMBER-2, and CLIMBER LPJ, respectively, temperature decreases by $0.4,0.3$, and $0.3^{\circ}$ $\mathrm{C}$, and atmospheric $\mathrm{CO}_{2}$ decreases by a maximum of $3.4,1.1$, and $1.2 \mathrm{ppm}$. In response to a 1258 ice core event-equivalent eruption, temperature decreases by $1.8,1.4$, and $1.4^{\circ} \mathrm{C}$ and atmospheric $\mathrm{CO}_{2}$ decreases by 15,5 , and $5 \mathrm{ppm}$. Despite qualitative similarities in the temperature and atmospheric $\mathrm{CO}_{2}$ responses across all models, there are a number of significant differences in modelled carbon cycle responses. The $\mathrm{CO}_{2}$ decline is explained differently in each model, both with respect to the behaviour of carbon pools and the timescales on which they respond.

[48] The response of the vegetation carbon pool is a key model difference, with SIMEARTH modelling first increased uptake of carbon, due to an increase in productivity at lower temperatures, and then a decrease in carbon, due to the limitation of decreasing atmospheric $\mathrm{CO}_{2}$. Conversely, CLIMBER-2 simulates a loss of vegetation in response to volcanic cooling, while CLIMBER LPJ simulates a larger vegetation loss. In SIMEARTH and CLIMBER LPJ, the carbon cycle responds more slowly than climate, whereas in CLIMBER-2, the carbon cycle response occurs on similar timescales to the climate response, due to the faster response of soil carbon in that model.

[49] Determining which of the modelled carbon cycle responses is most realistic is challenging. The largest eruption naturally has the greatest and most identifiable $\mathrm{CO}_{2}$ signal. Yet ice core observations of atmospheric $\mathrm{CO}_{2}$, such as that derived from measurements at Law Dome [Etheridge et al., 1996], as well as recent measurements in the West fAntarctic Ice core [Ahn et al., 2012], do not indicate a $\mathrm{CO}_{2}$ drop after the 1258 eruption. On the one hand, this could be due to the effects of natural smoothing during irn deposition. On the other hand, the cooling signal of the 1258 eruption in temperature reconstructions of the last millennium is quite small on the decadal scale [Mann et al., 2008]; therefore, data concerning this eruption may lack the precision required to form a useful constraint on the carbon cycle response to cooling, especially since the exact geographical location of this eruption is uncertain. Furthermore, there are currently limited data that can be employed to validate the vegetation and soil carbon response of this eruption. There are site-specific examples of carbon isotopes in soil organic matter being used to evaluate past changes in vegetation [e.g., de Freitas et al., 2001; McClaran and Umlauf, 2000; Pessenda et al., 2010], and GPP can be derived from measurements of ${ }^{18} \mathrm{O}$ in atmospheric oxygen from ice cores [Ciais et al., 2012], but due to uncertainties relating to the time resolution and dating of cores, such data are not helpful for the very short timescales investigated in this study.

[50] More comparisons can be drawn for the Pinatuboequivalent eruption, although the absence of other forcings that may be relevant (e.g., solar, other GHGs) in the models, along with the presence of other signals in the observational record (e.g., ENSO variability), makes a direct comparison difficult. After Pinatubo, an enhanced carbon sink of approximately $2 \mathrm{GtC} / \mathrm{yr}$ was observed [Angert et al., 2004], and this is comparable to model responses. However, as already noted, the processes underlying this enhanced sink are uncertain. As such, it is likely that repeating the study with another set of models, incorporating a different level of process understanding, would yield different results. The increase in diffuse light associated with scattering by volcanic sulphate aerosols, which is not accounted for in the ESMs used here, may also be a factor. Photosynthesis is more efficient under diffuse light conditions, an effect which has been shown to enhance the land carbon sink [Mercado et al., 2009]. However, Lucht et al. [2002] found that the effect of cooling on NPP and soil respiration can also provide an explanation for the enhanced land carbon sink after Pinatubo. Eliseev and Mokhov [2011] also showed that a model that neglects the effect of diffuse radiation can still reproduce changes in atmospheric carbon associated with volcanic eruptions, through stronger suppression of soil respiration.

[51] As mentioned previously, volcanic eruptions are often considered a natural analogue to stratospheric aerosol injections as a geoengineering technique. The models in this study all contain reasonable parameterizations, yet while they converge with respect to the temperature change associated with volcanic forcing, they simulate different carbon cycle responses. This result suggests that key uncertainties remain in our understanding of the carbon cycle response to temperature, and that these uncertainties must be resolved before the impact of stratospheric aerosol injections on the carbon cycle can be understood. While the overall sensitivity of land carbon to atmospheric $\mathrm{CO}_{2}$ change $\left(\beta_{\mathrm{L}}\right)$ is relatively consistent across the models, the dynamics of vegetation carbon are an area of particular intermodel variability. Eliseev [2012] suggests that geoengineering could suppress gross primary production, decreasing vegetation carbon, a conclusion which is supported across models of varying complexity in $\mathrm{fthis}$ study; even in SIMEARTH, the initial enhancement of vegetation carbon in response to temperature change eventually gives way to a decrease in response to change in atmospheric $\mathrm{CO}_{2}$. Yet Volodin et al. [2011] suggest that an increase in GPP is likely due to such geoengineering, as a result of the effects of diffuse light. Meanwhile, the post-Pinatubo literature also demonstrates that there is significant uncertainty associated with understanding of the land carbon response to volcanic stratospheric aerosol forcing, suggesting that this should be a particular focus for future research, to improve our ability to model climate-carbon cycle interactions. The addition of new processes to the models, such as diffuse light effects on GPP, may help to resolve some of this uncertainty.

[52] Acknowledgment. The research leading to these results has received funding from the European Community's Seventh Framework Programme (FP7 2007-2013) under grant agreement 238366.

\section{References}

Ahn, J., E. J. Brook, L. Mitchell, J. Rosen, J. R. McConnell, K. Taylor, D. Etheridge, and M. Rubino (2012), Atmospheric CO2 over the last 1000 years: A high-resolution record from the West Antarctic Ice Sheet (WAIS) Divide ice core, Global Biogeochem. Cycles, 26, GB2027, doi:10.1029/2011GB004247.

Angert, A., S. Biraud, C. Bonfils, W. Buermann, and I. Fung (2004), CO2 seasonality indicates origins of post-Pinatubo sink, Geophys. Res. Lett., 31, L11103, doi:10.1029/2004GL019760. 


\section{FOLEY ET AL.: ESM CARBON CYCLE RESPONSE TO VOLCANISM}

Arora, V., et al. (2013), Carbon-concentration and carbon-climate feedbacks in CMIP5 Earth system models, J. Climate, doi:10.1175/JCLI-D-12-00494.1.

Baker, D. F., et al. (2006), TransCom 3 inversion intercomparison: Impact of transport model errors on the interannual variability of regional CO2 fluxes, 1988-2003, Global Biogeochem. Cycles, 20, GB1002, doi:10.1029/2004GB002439.

Barford, C. C., S. C. Wofsy, M. L. Goulden, J. W. Munger, E. H. Pyle, S. P. Urbanski, L. Hutyra, S. R. Saleska, D. Fitzjarrald, and K. Moore (2001), Factors controlling long- and short-term sequestration of atmospheric CO2 in a mid-latitude forest, Science, 294(5547), 1688-1691, doi:10.1126/science.1062962.

Bauer, E., M. Claussen, V. Brovkin, and A. Huenerbein (2003), Assessing climate forcings of the Earth system for the past millennium, Geophys. Res. Lett., 30(6), 1276, doi:10.1029/2002GL016639.

Bradley, R. S. (1999), Paleoclimatology: Reconstructing Climates of the Quaternary, 2nd ed., Academic Press, San Diego, CA.

Brovkin, V., A. Ganopolski, and Y. Svirezhev (1997), A continuous climatevegetation classification for use in climate-biosphere studies, Ecol. Modell., 101(2-3), 251-261, doi:10.1016/S0304-3800(97)00049-5.

Brovkin, V., J. Bendtsen, M. Claussen, A. Ganopolski, C. Kubatzki, V. Petoukhov, and A. Andreev (2002), Carbon cycle, vegetation, and climate dynamics in the Holocene: Experiments with the CLIMBER-2 model, Global Biogeochem. Cycles, 16(4), 1139, doi:10.1029/ 2001GB001662.

Brovkin, V., S. J. Lorenz, J. Jungclaus, T. Raddatz, C. Timmreck, C. H. Reick, J. Segschneider, and K. Six (2010), Sensitivity of a coupled climate-carbon cycle model to large volcanic eruptions during the last millennium, Tellus $B$, 62(5), 674-681, doi:10.1111/j.1600-0889.2010.00471.x.

Buggisch, W., M. M. Joachimski, O. Lehnert, S. M. Bergström, J. E. Repetski, and G. F. Webers (2010), Did intense volcanism trigger the first Late Ordovician icehouse?, Geology, 38(4), 327-330, doi:10.1130/G30577.1.

Ciais, P., P. P. Tans, J. W. C. White, M. Trolier, R. J. Francey, J. A. Berry, D. R. Randall, P. J. Sellers, J. G. Collatz, and D. S. Schimel (1995), Partitioning of ocean and land uptake of $\mathrm{CO}_{2}$ as inferred by $\delta 13 \mathrm{C}$ measurements from the NOAA Climate Monitoring and Diagnostics Laboratory Global Air Sampling Network, J. Geophys. Res., 100(D3), 5051-5070, doi:10.1029/94JD02847.

Ciais, P., et al. (2012), Large inert carbon pool in the terrestrial biosphere during the Last Glacial Maximum, Nat. Geosci., 5(1), 74-79, doi:10.1038/ngeo1324.

Claussen, M., V. Brovkin, A. Ganopolski, C. Kubatzki, V. Petoukhov, and S. Rahmstorf (1999), A new model for climate system analysis: Outline of the model and application to palaeoclimate simulations, Environ. Model. Assess., 4(4), 209-216, doi:10.1023/A:1019016418068.

Cole-Dai, J. (2010), Volcanoes and climate, Wiley Interdiscip. Rev. Clim. Change, 1(6), 824-839, doi:10.1002/wcc.76.

Crowley, T. J. (2000), Causes of climate change over the past 1000 years, Science, 289, 270-277, doi:10.1126/science.289.5477.270.

Cox, P., and C. Jones (2008), Illuminating the modern dance of climate and $\mathrm{CO}_{2}$, Science, 321(5849), 1642-1644.

de Freitas, H. A., L. C. R. Pessenda, R. Aravena, S. E. M. Gouveia A. de Souza Ribeiro, and R. Boulet (2001), Late quaternary vegetation dynamics in the Southern Amazon Basin inferred from carbon isotopes in soil organic matter, Quat. Res., 55(1), 39-46, doi:10.1006/qres.2000.2192.

D'Arrigo, R., R. Wilson, B. Liepert, and P. Cherubini (2008), On the "Divergence Problem" in Northern Forests: A review of the tree-ring evidence and possible causes, Global Planet. Change, 60(3-4), 289-305, doi:10.1016/j.gloplacha.2007.03.004.

Eby, M., et al. (2013), Historical and idealized climate model experiments: an intercomparison of Earth system models of intermediate complexity, Clim. Past, 9, 1111-1140, doi:10.5194/cp-9-1111-2013.

Eliseev, A. V., and I. I. Mokhov (2011), Uncertainty of climate response to natural and anthropogenic forcings due to different land use scenarios, Adv. Atmos. Sci., 28(5), 1215-1232, doi:10.1007/s00376-010-0054-8.

Eliseev, A. V. (2012), Climate change mitigation via sulfate injection to the stratosphere: impact on the global carbon cycle and terrestrial biosphere, Atmos. Oceanic Opt., 25(6), 405-413.

Etheridge, D. M., L. P. Steele, R. L. Langenfelds, R. J. Francey, J.-M. Barnola, and V. I. Morgan (1996), Natural and anthropogenic changes in atmospheric $\mathrm{CO} 2$ over the last 1000 years from air in Antarctic ice and firn, J. Geophys. Res., 101(D2), 4115-4128, doi:10.1029/95JD03410.

Feulner, G. (2011), Are the most recent estimates for Maunder Minimum solar irradiance in agreement with temperature reconstructions?, Geophys. Res. Lett., 38, L16706, doi:10.1029/2011GL048529.

Fischer, H., M. Wahlen, J. Smith, D. Mastroianni, and B. Deck (1999), Ice core records of atmospheric $\mathrm{CO} 2$ around the last three glacial terminations, Science, 283(5408), 1712-1714, doi:10.1126/science.283.5408.1712.

Foley, J. A., and N. Ramankutty (2004), A primer on the terrestrial carbon cycle: What we don't know but should, in The Global Carbon Cycle: Integrating
Humans, Climate, and The Natural World, edited by C. B. Field, and M. R. Raupach, pp. 279-294, Island Press, Washington, D.C. [online]. Available from: http://www.cabdirect.org/abstracts/20043080434.html?freeview=true (Accessed 14 August 2012)

Foster, G., and S. Rahmstorf (2011), Global temperature evolution 1979 2010, Environ. Res. Lett., 6, 044022, doi:10.1088/1748-9326/6/4/044022. Frank, D. C., J. Esper, C. C. Raible, U. Büntgen, V. Trouet, B. Stocker, and F. Joos (2010), Ensemble reconstruction constraints on the global carbon cycle sensitivity to climate, Nature, 463(7280), 527-530, doi:10.1038/nature08769.

Friedlingstein, P., et al. (2006), Climate-carbon cycle feedback analysis: Results from the C4 MIP model intercomparison, J. Clim., 19(14), 3337-3353, doi:10.1175/JCLI3800.1

Friend, A. D. (2011), Response of Earth's surface temperature to radiative forcing over A.D. 1-2009, J. Geophys. Res., 116, D13112, doi:10.1029/ 2010JD015143.

Frölicher, T. L., F. Joos, C. C. Raible, and J. L. Sarmiento (2013), Atmospheric $\mathrm{CO}_{2}$ response to volcanic eruptions: The role of ENSO, season, and variability, Global Biogeochem. Cycles, 27, 239-251 doi:10.1002/gbc. 20028 .

Ganopolski, A., V. Petoukhov, S. Rahmstorf, V. Brovkin, M. Claussen, A. Eliseev, and C. Kubatzki (2001), CLIMBER-2: A climate system model of intermediate complexity. Part II: Model sensitivity, Clim. Dyn. 17(10), 735-751, doi:10.1007/s003820000144.

Gerlach, T. (2011), Volcanic versus anthropogenic carbon dioxide, Eos Trans. $A G U$, 92(24), 201-202, doi:10.1029/2011EO240001.

Gregory, J. M., C. D. Jones, P. Cadule, and P. Friedlingstein (2009), Quantifying carbon cycle feedbacks, J. Clim., 22(19), 5232-5250, doi:10.1175/2009JCLI2949.1.

Gu, L., D. D. Baldocchi, S. C. Wofsy, J. W. Munger, J. J. Michalsky, S. P. Urbanski, and T. A. Boden (2003), Response of a deciduous fores to the Mount Pinatubo eruption: Enhanced photosynthesis, Science, 299(5615), 2035-2038, doi:10.1126/science.1078366.

Hansen, J., et al. (2005), Efficacy of climate forcings, J. Geophys. Res., 110, D18104, doi:10.1029/2005JD005776.

Hegerl, G. C., T. J. Crowley, W. T. Hyde, and D. J. Frame (2006), Climate sensitivity constrained by temperature reconstructions over the past seven centuries, Nature, 440(7087), 1029-1032, doi:10.1038/nature04679.

Horn, J. E., and K. Schulz (2011), Identification of a general light use efficiency model for gross primary production, Biogeosciences, $8(4)$ 999-1021, doi:10.5194/bg-8-999-2011.

Indermühle, A., B. Stauffer, T. F. Stocker, D. Raynaud, and J. M. Barnola (1999), Early Holocene atmospheric $\mathrm{CO}_{2}$ concentrations, Science, 286(5446), 1815.

Jones, P. D., et al. (2009), High-resolution palaeoclimatology of the last millennium: a review of current status and future prospects, The Holocene, 19(1), 3-49, doi:10.1177/0959683608098952.

Koch, G. W., and H. A. Mooney (eds.) (1996), Carbon Dioxide and Terrestrial Ecosystems, Academic Press, San Diego, CA

Krakauer, N. Y., and J. T. Randerson (2003), Do volcanic eruptions enhance or diminish net primary production? Evidence from tree rings, Global Biogeochem. Cycles, 17(4), 1118, doi:10.1029/2003GB002076.

Lean, J. L., and D. H. Rind (2008), How natural and anthropogenic influences alter global and regional surface temperatures: 1889 to 2006 , Geophys. Res. Lett., 35, L18701, doi:10.1029/2008GL034864.

Lucht, W., I. C. Prentice, R. B. Myneni, S. Sitch, P. Friedlingstein W. Cramer, P. Bousquet, W. Buermann, and B. Smith (2002), Climatic control of the high-latitude vegetation greening trend and Pinatubo effect Science, 296(5573), 1687-1689, doi:10.1126/science.1071828.

Lüthi, D., et al. (2008), High-resolution carbon dioxide concentration record 650,000-800,000 years before present, Nature, 453(7193), 379-382, doi:10.1038/nature06949.

Mann, M. E. (2002), The value of multiple proxies, Science, 297(5586), 1481-1482, doi:10.1126/science.1074318.

Mann, M. E., Z. Zhang, M. K. Hughes, R. S. Bradley, S. K. Miller S. Rutherford, and F. Ni (2008), Proxy-based reconstructions of hemispheric and global surface temperature variations over the past two millennia, Proc. Natl. Acad. Sci. U. S. A., 105(36), 13,252-13,257, doi:10.1073/ pnas.0805721105. [online] Available from: http://www.pnas.org/content early/2008/09/02/0805721105 (Accessed 25 February 2013).

Mann, M. E., J. D. Fuentes, and S. Rutherford (2012), Underestimation of volcanic cooling in tree-ring-based reconstructions of hemispheric temperatures, Nat. Geosci., 5(3), 202-205, doi:10.1038/ngeo1394.

McClaran, M. P., and M. Umlauf (2000), Desert grassland dynamics estimated from carbon isotopes in grass phytoliths and soil organic matter J. Veg. Sci., 11(1), 71-76, doi:10.2307/3236777.

McDermott, F. (2004), Palaeo-climate reconstruction from stable isotope variations in speleothems: A review, Quat. Sci. Rev., 23(7-8), 901-918, doi:10.1016/j.quascirev.2003.06.021.

Mercado, L. M., N. Bellouin, S. Sitch, O. Boucher, C. Huntingford, M. Wild, and P. M. Cox (2009), Impact of changes in diffuse radiation 


\section{FOLEY ET AL.: ESM CARBON CYCLE RESPONSE TO VOLCANISM}

on the global land carbon sink, Nature, 458(7241), 1014-1017, doi:10.1038/nature 07949 .

Miller, G. H., et al. (2012), Abrupt onset of the Little Ice Age triggered by volcanism and sustained by sea-ice/ocean feedbacks, Geophys. Res. Lett., 39, L02708, doi:10.1029/2011GL050168.

Parfitt, L., and L. Wilson (2008), Fundamentals of Physical Volcanology, 1st ed., Blackwell, Malden, MA.

Pessenda, L. C. R., S. E. M. Gouveia, A. de Souza Ribeiro, P. E. De Oliveira, and R. Aravena (2010), Late Pleistocene and Holocene vegetation changes in northeastern Brazil determined from carbon isotopes and charcoal records in soils, Palaeogeogr. Palaeoclimatol. Palaeoecol., 297(3-4), 597-608, doi:10.1016/j.palaeo.2010.09.008.

Petoukhov, V., A. Ganopolski, V. Brovkin, M. Claussen, A. Eliseev, C. Kubatzki, and S. Rahmstorf (2000), CLIMBER-2: A climate system model of intermediate complexity. Part I: Model description and performance for present climate, Clim. Dyn., 16(1), 1-17, doi:10.1007/ PL00007919.

Plattner, G.-K., et al. (2008), Long-term climate commitments projected with climate-carbon cycle models, J. Clim., 21(12), 2721-2751, doi:10.1175/ 2007JCLI1905.1.

Potter, C. S., J. T. Randerson, C. B. Field, P. A. Matson, P. M. Vitousek, H. A. Mooney, and S. A. Klooster (1993), Terrestrial ecosystem production: A process model based on global satellite and surface data, Global Biogeochem. Cycles, 7(4), 811-841, doi:10.1029/93GB02725.

Rafelski, L. E., S. C. Piper, and R. F. Keeling (2009), Climate effects on atmospheric carbon dioxide over the last century, Tellus B, 61(5), 718-731.

Rampino, M. R., and S. Self (1993), Climate-volcanism feedback and the Toba eruption of $\sim 74,000$ years ago, Quat. Res., 40(3), 269-280, doi:10.1006/qres.1993.1081.

Rasch, P. J., S. Tilmes, R. P. Turco, A. Robock, L. Oman, C.-C. (Jack) Chen, G. L. Stenchikov, and R. R. Garcia (2008), An overview of geoengineering of climate using stratospheric sulphate aerosols, Philos. Trans. R. Soc. A, 366(1882), 4007-4037, doi:10.1098/rsta.2008.0131.

Robock, A. (1979), The "Little Ice Age": Northern Hemisphere average observations and model calculations, Science, 206, 1402-1404.

Robock, A. (2000), Volcanic eruptions and climate, Rev. Geophys., 38(2), 191-219, doi:10.1029/1998RG000054.

Roderick, M., G. Farquhar, S. Berry, and I. Noble (2001), On the direct effect of clouds and atmospheric particles on the productivity and structure of vegetation, Oecologia, 129(1), 21-30, doi:10.1007/s004420100760.

Santer, B. D., T. M. L. Wigley, C. Doutriaux, J. S. Boyle, J. E. Hansen, P. D. Jones, G. A. Meehl, E. Roeckner, S. Sengupta, and K. E. Taylor (2001), Accounting for the effects of volcanoes and ENSO in comparisons of modeled and observed temperature trends, J. Geophys. Res., 106(D22), 28,033-28,059, doi:10.1029/2000JD000189.
Schimel, D. S., B. H. Braswell, E. A. Holland, R. McKeown, D. S. Ojima, T. H. Painter, W. J. Parton, and A. R. Townsend (1994), Climatic, edaphic, and biotic controls over storage and turnover of carbon in soils, Global Biogeochem. Cycles, 8(3), 279-293, doi:10.1029/94GB00993.

Schleussner, C. F., and G. Feulner (2013), A volcanically triggered regime shift in the subpolar North Atlantic Ocean as a possible origin of the Little Ice Age, Clim. Past, 9(3), 1321-1330, doi:10.5194/cp-9-1321-2013.

Schönwiese, C. D. (1988), Volcanic activity parameters and volcanism-climate relationships within the recent centuries, Atmosfera, 1(3), 141-156.

Segschneider, J., A. Beitsch, C. Timmreck, V. Brovkin, T. Ilyina, J. Jungclaus, S. J. Lorenz, K. D. Six, and D. Zanchettin (2013), Impact of an extremely large magnitude volcanic eruption on the global climate and carbon cycle estimated from ensemble Earth System Model simulations, Biogeosciences, 10(2), 669-687, doi:10.5194/bg-10-669-2013.

Sitch, S., et al. (2003), Evaluation of ecosystem dynamics, plant geography and terrestrial carbon cycling in the LPJ dynamic global vegetation model, Global Change Biol., 9(2), 161-185, doi:10.1046/j.13652486.2003.00569.x.

Sitch, S., V. Brovkin, W. von Bloh, D. van Vuuren, B. Eickhout, and A. Ganopolski (2005), Impacts of future land cover changes on atmospheric CO2 and climate, Global Biogeochem. Cycles, 19, GB2013, doi:10.1029/2004GB002311.

Takahashi, T., et al. (2002), Global sea-air CO2 flux based on climatological surface ocean $\mathrm{pCO} 2$, and seasonal biological and temperature effects, Deep Sea Res. Part II, 49(9-10), 1601-1622, doi:10.1016/S0967-0645 (02)00003-6.

Timmreck, C. (2012), Modeling the climatic effects of large explosive volcanic eruptions, Wiley Interdiscip. Rev. Clim. Change, 3(6), 545-564.

Volodin, E. M., S. V. Kostrykin, and A. G. Ryaboshapko (2011), Simulation of climate change induced by injection of sulfur compounds into the stratosphere, Izv. Atmos. Oceanic Phys., 47(4), 430-438.

Wigley, T. M. L. (2000), ENSO, volcanoes and record-breaking temperatures, Geophys. Res. Lett., 27(24), 4101-4104, doi:10.1029/2000GL012159.

Wigley, T. M. L. (2006), A combined mitigation/geoengineering approach to climate stabilization, Science, 314(5798), 452-454, doi:10.1126/ science. 1131728

Yang, F., and M. E. Schlesinger (2001), Identification and separation of Mount Pinatubo and El Niño-Southern Oscillation land surface temperature anomalies, J. Geophys. Res., 106(D14), 14,757-14,770, doi:10.1029/ 2001JD900146.

Zickfeld, K., M. Eby, H. D. Matthews, A. Schmittner, and A. J. Weaver (2011), Nonlinearity of carbon cycle feedbacks, J. Clim., 24(16), 4255-4275, doi:10.1175/2011JCLI3898.1.

Zielinski, G. A. (2000), Use of paleo-records in determining variability within the volcanism-climate system, Quat. Sci. Rev., 19(1-5), 417-438, doi:10.1016/S0277-3791(99)00073-6. 